\title{
Reconditioning lungs donated after cardiac death using short-term hypothermic machine perfusion.
}

\section{AUTHOR(S):}

Nakajima, Daisuke; Chen, Fengshi; Okita, Kenji; Motoyama, Hideki; Hijiya, Kyoko; Ohsumi, Akihiro; Sakamoto, Jin; ... Aoyama, Akihiro; Bando, Toru; Date, Hiroshi

\section{CITATION:}

Nakajima, Daisuke ...[et al]. Reconditioning lungs donated after cardiac death using shortterm hypothermic machine perfusion.. Transplantation 2012, 94(10): 999-1004

\section{ISSUE DATE:}

2012-11-27

URL:

http://hdl.handle.net/2433/184449

\section{RIGHT:}

(c) 2012 Lippincott Williams \& Wilkins, Inc.; この論文は出版社版であり ません。引用の際には出版社版をご確認ご利用ください。; This is not the published version. Please cite only the published version. 


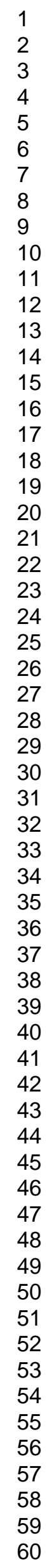

SCHOLARONE ${ }^{\mathrm{T}}$

Manuscripts

14

15

16

17

18

19

20

22

23

25

26

27

29

30

32

33

34

35

36

39

40

41

42

43

45

46

47

48

49

50

52

53

54

56

57

58

59

60 
1 The title: Reconditioning lungs donated after cardiac death using short-term

2 hypothermic machine perfusion ${ }^{1}$

3

4 Authors: Daisuke Nakajima ${ }^{2}$, Fengshi Chen ${ }^{2}$, Kenji Okita ${ }^{2}$, Hideki Motoyama ${ }^{2}$,

5 Kyoko Hijiya ${ }^{2}$, Akihiro Ohsumi ${ }^{2}$, Jin Sakamoto ${ }^{2}$, Tetsu Yamada ${ }^{2}$, Masaaki Sato ${ }^{2}$,

6 Akihiro Aoyama ${ }^{2}$, Toru Bando ${ }^{2}$, Hiroshi Date ${ }^{2}$

7

82 Department of Thoracic Surgery, Graduate School of Medicine, Kyoto University,

$9 \quad$ Kyoto, Japan

10

11 Key words: Hypothermic machine perfusion, DCD, Ischemia-reperfusion injury, 12 Lung transplantation, ROS

13

14 Word count: abstract 248 words, text 2997 words

15 Number of tables and figures: color 1 figure, total 5 figures

16

17

18

19

20

21

22

23

24

25
Address for correspondence: corresponding author: Daisuke Nakajima, MD mailing address: 54 Shogoin-Kawahara-cho, Sakyo-ku, Kyoto, Japan telephone number: $+81-75-751-4975$ fax number: $+81-75-751-4974$ e-mail address:daink@kuhp.kyoto-u.ac.jp 


\section{Footnotes}

$2{ }^{1}$ Part of this work was presented at the XXIV International Congress of The

3 Transplantation Society, July 15-20, 2012, Berlin, Germany

4

$5 \quad 254$ Shogoin-Kawahara-cho, Sakyo-ku, Kyoto, 606-8507, Japan

6

7 Daisuke Nakajima, Fengshi Chen, Kenji Okita, Hideki Motoyama, Kyoko Hijiya,

8 Akihiro Ohsumi, Jin Sakamoto and Tetsu Yamada participated in the performance

9 of the research.

10 Daisuke Nakajima, Fengshi Chen, Kenji Okita, Hideki Motoyama, Kyoko Hijiya,

11 Akihiro Ohsumi, Jin Sakamoto, Tetsu Yamada, Masaaki Sato, Akihiro Aoyama,

12 Toru Bando and Hiroshi Date participated in the research design.

13 Daisuke Nakajima, Fengshi Chen, Toru Bando and Hiroshi Date participated in the

14 writing of the paper.

15

16 All authors declare no potential conflict of interest. 


\section{Abbreviations}

2 ATP: adenosine triphosphate

3 BAL: bronchoalveolar lavage

4 DCD: donation after cardiac death

$5 \quad$ EVLP: ex vivo lung perfusion

$6 \quad \mathrm{FiO}_{2}$ : inspired oxygen fraction

7 HMP: hypothermic machine perfusion

8 MDA: malondialdehyde

9 PawP: peek airway pressure

10 PEEP: positive end-expiratory pressure

11 ROS: reactive oxygen species

12 SCS: static cold storage

13 TBA: thiobarbituric acid

14 TLR: Toll-like receptor 
1 Abstract

2 Background. Hypothermic machine perfusion (HMP) is widely used to preserve

3 kidneys and livers for transplantation. This study investigated whether short-term

4 HMP could improve the quality of lungs donated after cardiac death (DCD).

$5 \quad$ Methods. In a clinically relevant uncontrolled DCD model, beagles were divided into

62 groups $(\mathrm{n}=5$ each): $4 \mathrm{~h}$ of warm ischemia $+14 \mathrm{~h}$ of static cold storage (SCS group)

7 or $4 \mathrm{~h}$ of warm ischemia $+12 \mathrm{~h}$ of static cold storage, followed by $2 \mathrm{~h}$ of HMP (HMP

8 group). HMP was performed using centrifugal perfusion with STEEN solution at

9 around $10^{\circ} \mathrm{C}$. In both groups, the left lungs were then transplanted and reperfused

10 for $4 \mathrm{~h}$ to evaluate the posttransplant lung functions.

11 Results. HMP was performed safely, not inducing any oxidative damage. The 12 dynamic pulmonary compliance was stable during HMP, while the pulmonary 13 vascular resistance significantly decreased. HMP microscopically eliminated 14 residual microthrombi in the donor lungs just before transplantation. The lung 15 tissue adenosine triphosphate (ATP) levels $4 \mathrm{~h}$ after reperfusion were significantly 16 higher in the HMP group compared with the SCS group. The serum 17 malondialdehyde levels and proinflammatory cytokine levels in the bronchoalveolar 18 lavage (BAL) fluid $4 \mathrm{~h}$ after reperfusion were significantly lower in the HMP group 19 than in the SCS group. The physiological lung functions during reperfusion were 20 significantly better in the HMP group compared to the SCS group. HMP also 21 significantly reduced ischemia-reperfusion injury in the microscopic findings.

22 Conclusions. Short-term HMP could resuscitate ischemically damaged DCD lungs, 23 and ameliorate ischemia-reperfusion injury. 


\section{Introduction}

2 Lung transplantation has become a mainstay of therapy for end-stage lung diseases.

3 However, there has been a progressive increase in the number of patients on the

4 waiting list, which continually exceeds the number of available organs. The use of

5 uncontrolled DCD donors has been employed to resolve this problem (1-3). Warm

6 ischemia inevitably occurs in uncontrolled DCD donors, and may cause ischemia-

7 reperfusion injury after transplantation. Severe ischemia-reperfusion injury leads

8 to primary graft dysfunction, and remains a significant cause of early morbidity and

9 mortality after lung transplantation (4). The inhibition of ischemia-reperfusion

10 injury is, therefore, crucial to facilitate lung transplantation from uncontrolled DCD

11 donors.

12 Warm ischemia impairs the mitochondrial electron transport chain, 13 resulting in decreased ATP production, and also decreases the efficacy of the 14 mitochondrial antioxidant system (5,6). Depending on its severity, the 15 reintroduction of oxygen at reperfusion can lead to a significant production of 16 reactive oxygen species (ROS), which induces the upregulation of molecules on the 17 cell surface and the release of proinflammatory mediators $(4,7)$.

18 Hypothermic machine perfusion (HMP) has been used to preserve kidneys 19 and livers for transplantation, with better results than static cold storage (SCS) $20(8,9)$. HMP is associated with a reduced risk of delayed graft function and improved 21 graft survival, compared with SCS. HMP is based on the concept that the oxidative 22 energy production by the mitochondrial electron transport would be sustained 23 under hypothermia (10). We previously demonstrated that short-term HMP, which 24 helped recover the ATP production by the mitochondrial electron transport chain, 
1 ameliorated ischemia- reperfusion injury with decreased oxidative damage during

2 reperfusion in an isolated rat lung perfusion model (11).

In the present study, we used a canine transplantation model mirroring the

4 clinical situation to investigate whether short-term HMP could improve the

5 mitochondrial function damaged by warm ischemia, and decrease the oxidative

6 damage and production of proinflammatory cytokines during reperfusion, thereby

7 reducing ischemia- reperfusion injury.

\section{Results}

\section{Physiological lung functions during HMP}

12 The influent variables (temperature, solutes, $\mathrm{PO}_{2}$ and $\mathrm{PCO}_{2}$ levels) were stable 13 during 120 min of HMP. The temperature was maintained at a mean of $9.26 \pm$ $140.88^{\circ} \mathrm{C}$, ranging from 7.9 to $10.5^{\circ} \mathrm{C}$. There was little variation in any solute during 15 the HMP time $\left(\mathrm{Na}^{+} 144.93 \pm 0.70 \mathrm{mmol} / \mathrm{L}, \mathrm{K}^{+} 5.49 \pm 0.28 \mathrm{mmol} / \mathrm{L}, \mathrm{Ca}^{2+} 0.85 \pm 0.03\right.$ $16 \mathrm{mmol} / \mathrm{L}$ ). The $\mathrm{PH}, \mathrm{PO}_{2}$ and $\mathrm{PCO}_{2}$ levels were also maintained at means of $7.20 \pm$ $17 \quad 0.04,113.73 \pm 1.03 \mathrm{mmHg}$ and $37.67 \pm 5.67 \mathrm{mmHg}$, respectively.

The dynamic pulmonary compliance was stable during HMP. The dynamic pulmonary compliance at baseline and after 120 min of HMP were 25.77 \pm 7.18 $\mathrm{ml} / \mathrm{cmH}_{2} \mathrm{O}$ and $26.46 \pm 7.10 \mathrm{ml} / \mathrm{cmH}_{2} \mathrm{O}$, respectively $(\mathrm{P}=0.76 ;$ Fig. $1 \mathrm{~A})$. The

21 pulmonary vascular resistance gradually decreased during HMP. The pulmonary vascular resistance after 60, 90, and 120 min of HMP significantly decreased, in 23 comparison to that at the baseline of $\operatorname{HMP}(\mathrm{P}<0.05$; Fig. 1B). 
1 Microthrombi in the donor lungs just before transplantation

2 The biopsy specimens were collected from 5 donor lungs in the HMP group and 4

3 donor lungs in the SCS group. Residual microthrombi in the donor lungs just before

4 transplantation were microscopically assessed to prove the wash-out effects of HMP.

5 Residual blood cells or blood clots in the capillaries were observed more often in the

6 SCS group (4/4 specimens; Fig. 1C) compared with the HMP group (0/5 specimens;

$7 \quad$ Fig. 1D).

8

$9 \quad$ Lung tissue ATP levels

10 The lung tissue ATP levels were measured before cardiac arrest, after warm 11 ischemia, and $4 \mathrm{~h}$ after reperfusion to evaluate the mitochondrial function. In the 12 HMP group, the lung tissue ATP levels, which decreased during warm ischemia, 13 were significantly improved $4 \mathrm{~h}$ after reperfusion $(\mathrm{P}<0.05$; Fig. 2). Moreover, the 14 lung tissue ATP levels $4 \mathrm{~h}$ after reperfusion were significantly higher in the HMP group than in the SCS group $(\mathrm{P}<0.05$; Fig. 2). The ATP levels before cardiac arrest and after warm ischemia were $6.33 \pm 0.79$ and $2.68 \pm 1.07 \mathrm{nmol} / \mathrm{mg} \cdot \mathrm{dw}$, respectively.

17 The ATP levels $4 \mathrm{~h}$ after reperfusion in the HMP group and in the SCS group were $4.53 \pm 0.38$ and $3.07 \pm 0.94 \mathrm{nmol} / \mathrm{mg} \cdot \mathrm{dw}$, respectively.

\section{Oxidative damage during HMP and reperfusion}

21 Malondialdehyde is one of the most commonly used markers for lipid peroxidation

22 (12). The malondialdehyde levels in the perfusate were measured at baseline and

23 after 120 min of HMP to assess the oxidative damage that occurred during HMP.

24 HMP did not increase the malondialdehyde levels in the perfusate; the 
1 malondialdehyde levels at baseline and after 120 min of HMP were 2.23 \pm 0.49 and

$2 \quad 2.06 \pm 0.45 \mathrm{nmol} / \mathrm{ml}$, respectively ( $\mathrm{P}=0.69$; Fig. 3A). The serum malondialdehyde

3 levels were measured $4 \mathrm{~h}$ after reperfusion to evaluate the oxidative damage that

4 occurred during reperfusion. The serum malondialdehyde levels were significantly

5 lower in the HMP group compared with the SCS group (HMP group: $1.55 \pm 0.74$

$6 \mathrm{nmol} / \mathrm{ml}$, SCS group: $3.63 \pm 1.15 \mathrm{nmol} / \mathrm{ml}, \mathrm{P}<0.05$; Fig. 3B).

\section{Proinflammatory cytokine levels in BAL fluid after reperfusion}

9 The TNF- $\alpha$ and IL-6 levels in the BAL fluid were measured $4 \mathrm{~h}$ after reperfusion.

10 The TNF- $\alpha$ levels were significantly lower in the HMP group than in the SCS

11 group (HMP group: 5.83 $\pm 3.22 \mathrm{pg} / \mathrm{ml}$, SCS group: $54.15 \pm 29.36 \mathrm{pg} / \mathrm{ml}, \mathrm{P}<0.01$; Fig.

12 3C). The IL-6 levels were also significantly lower in the HMP group compared with 13 the SCS group (HMP group: $1.55 \pm 0.74 \mathrm{pg} / \mathrm{ml}$, SCS group: $3.63 \pm 1.15 \mathrm{pg} / \mathrm{ml}, \mathrm{P}<0.05$;

14 Fig. 3D).

\section{Physiological lung functions during reperfusion}

17 The lung oxygenation and dynamic pulmonary compliance were significantly better 18 in the HMP group than those in the SCS group ( $\mathrm{P}<0.01$; Figs. $4 \mathrm{~A}$ and $\mathrm{B})$. The wet to dry lung weight ratio, indicating the severity of pulmonary edema, $4 \mathrm{~h}$ after reperfusion was significantly lower in the HMP group than that in the SCS group

21 (HMP group: 7.09 \pm 0.77 , SCS group: 12.03 \pm 4.05 ; $\mathrm{P}<0.05$; Fig. 4C).

23 Histological findings of ischemia-reperfusion injury

24 Severe interstitial and intra-alveolar edema, hemorrhage, infiltration of 
1 inflammatory cells in the air space or vessel wall, and hyaline formation were

2 detected in the SCS group $4 \mathrm{~h}$ after reperfusion. The acute lung injury score was

3 significantly lower in the HMP group in comparison to the SCS group (HMP group:

$4 \quad 22.6 \pm 6.80$, SCS group: $44.6 \pm 4.45, \mathrm{P}<0.01$; Fig. 5).

5

6

\section{Discussion}

8 The current study utilized a clinically relevant uncontrolled DCD model. We chose 4

$9 \mathrm{~h}$ of warm ischemia to possibly expand the donor pool for lung transplantation, 10 although the Madrid groups reported a maximum warm ischemic time of $2 \mathrm{~h}(3,13)$.

11 The retrieval of lungs after cardiac death requires an intermediate period to be 12 transported to the transplant center, so we added $12 \mathrm{~h}$ of SCS right before HMP. 13 Dutkowski et al. suggested that 1-2 $\mathrm{h}$ of HMP should be performed during the 14 recipient preparation without delay of the transplant procedure (10). We previously reported that $1 \mathrm{~h}$ of HMP significantly improved the rat lung tissue ATP levels, which had decreased during warm ischemia (11). In the current study, DCD lungs, which were injured by $4 \mathrm{~h}$ of warm ischemia and additional $12 \mathrm{~h}$ of cold ischemia, could be resuscitated by $2 \mathrm{~h}$ of HMP.

This study found that short-term HMP could be performed safely for DCD lungs, not inducing any significant amount of oxidative damage. We recently developed a reliable and reproducible technique for lung HMP in a large animal model, which demonstrated stable machine perfusion characteristics and excellent lung performance during $8 \mathrm{~h}$ of HMP (data not shown). The current study revealed that this technique could be used for reconditioning of ischemically damaged DCD 
1 lungs. None of the influent valuables showed spikes, and the dynamic pulmonary

2 compliance was also maintained during the entire period of HMP. Oxidative damage

3 under the exposure to oxygen at hypothermia has been demonstrated in studies on

4 isolated cell systems (14), while several studies in animal models demonstrated that

5 liver HMP resulted in minor oxidative damage $(15,16)$. The present study found

6 that short-term lung HMP did not cause oxidative stress during the perfusion,

7 which was indicated by the fact that the malondialdehyde levels in the perfusate

8 did not increase during HMP. Intravascular microthrombus formation, which results in an increase of

10 intrapulmonary shunting and pulmonary vascular resistance, is one of the major 11 causes of reperfusion injury in lung transplantation from DCD donors. The benefits 12 of additional retrograde flushing have been shown in experimental lung 13 transplantation (17-19). In the current study, a histological examination of the 14 donor lungs just before transplantation revealed fewer microthrombi in the HMP 15 group compared with the SCS group. This indicated that most of the residual 16 microthrombi wedged in the capillaries after the flushes were eliminated by HMP $17(9,20)$. Ventilation during perfusion results in better distribution of the preservation solution. A reduction of minute ventilation decreases the total amount of elastic stress imposed on cooled lungs (21). Therefore, the current study adopted the ventilation mode reduced respiratory rate and tidal volume during HMP, which

21 resulted in stable dynamic pulmonary compliance and the elimination of residual microthrombi. 
1 oxidative damage and production of proinflammatory cytokines during reperfusion.

2 Unlike other tissues that are transplanted, lung cells are able to maintain aerobic

3 metabolism using the oxygen present in the alveoli during SCS (22). In the SCS

4 group, the lung ATP levels, which decreased during warm ischemia, were improved

5 a little, but the improvement was significantly lower than that in the HMP group.

6 HMP could continue to provide the essential substrates for cell metabolism and

7 restore the lung tissue ATP levels. The reintroduction of oxygen to impaired

8 mitochondria at reperfusion leads to a significant production of ROS, which damage

9 proteins, lipids and DNA (6). The serum malondialdehyde levels after reperfusion

10 were significantly lower in the HMP group compared with the SCS group. HMP

11 possibly prevented the overload of oxygen upon reperfusion for the mitochondrial

12 electron transport chain by recovering the mitochondrial function before

13 reperfusion, and thus decreased production of ROS. Physical alterations of the

14 plasma membrane caused by ROS activate Toll-like receptors (TLRs), which are

15 expressed in endothelial cells and respiratory epithelial cells (7). The signal

16 transduction mediated by TLRs results in the activation of $\mathrm{NF}^{-} \kappa \mathrm{B}$, inducing the

17 production of proinflammatory cytokines and chemokines (7). Therefore, the

18 significantly increased levels of TNF- $\alpha$ and IL-6 in the SCS group might have

19 resulted from TLRs signaling in the pulmonary parenchymal cells, activated by the

20 significant increase in lipid peroxidation.

21 Normothermic perfusion has already been studied and proved to enable

22 organ viability assessment before transplantation, prolonged preservation, and

23 resuscitation from injuries $(23-27)$. It has been unknown which is more suitable for

24 organ preservation, hypothermic perfusion or normothermic perfusion. The organ is 
1 metabolically active under normothermic conditions, and thus normothermic

2 perfusion might allow better reconstitution of the lung tissue ATP stores. However,

3 normothermic perfusion requires that the physiological environment is completely

4 recreated with full nutritional support. Hypothermia decreases the metabolic rate

5 of the organ and could be used as a means for lung rest in the acutely injured lung

6 (21). This study demonstrated that HMP could continue to provide the essential

7 substrates for cell metabolism and restore the lung tissue ATP levels under the

8 slow-metabolic-rate conditions.

9 This study had several limitations. First, although we simulated a clinically

10 relevant uncontrolled DCD model, cardiac arrest was induced by intravenous

11 injection of potassium chloride. Such an abrupt cardiac arrest may have been

12 removed from clinical reality, in that there was not an agonal phase, which is an

13 important variable component of DCD (28). Second, the lung tissue ATP levels were

14 measured after warm ischemia and reperfusion. It might be easier to prove the

15 metabolic benefits of HMP if the ATP levels were measured just before and after

16 HMP.

17 In conclusion, short-term HMP could resuscitate DCD lungs injured by 18 prolonged ischemia, and ameliorate ischemia-reperfusion injury. First, short-term

19 HMP washed-out residual microthrombi in the donor lungs. Second, short-term

20 HMP improved the ATP production by the mitochondrial electron transport chain,

21 which led to the significant decrease in oxidative damage and production of

22 proinflammatory cytokines after reperfusion compared to SCS. 
1 Materials and Methods

$2 \quad$ Animals

3 Beagles weighing from 9 to $13 \mathrm{~kg}$ (Kitayama Labes Co. Ltd., Hongo Farm,

4 Yamaguchi, Japan) were used in this study. There was no significant difference in

5 the beagles' body weights between the two groups. All animals received humane

6 care in compliance with the Principals of Laboratory Animal Care, formulated by

7 the United States National Society for Medical Research, and the Guide for the

8 Care and Use of Laboratory Animals, prepared by the US Institute of Laboratory

9 Animal Resources and published by the National Institutes of Health (NIH

10 Publication 85-23, revised 1996). The study was approved by the Ethics Committee

11 of the Faculty of Medicine at Kyoto University, Japan.

12

13 Study design

14 The donor procedures, including anesthesia, induction of cardiac arrest, and antegrade and retrograde flushes of the lungs, were described in detail in a separate publication (29). Cardiac arrest was induced by the intravenous injection of potassium chloride $(0.5 \mathrm{mEq} / \mathrm{kg})$ without heparinization. Four hours after cardiac arrest, the donor lungs were retrieved, and then they were divided into 2 groups $(n=5$ each). The lungs in the SCS group were stored in an inflated state with oxygen fraction of 0.5 at $4^{\circ} \mathrm{C}$ for $14 \mathrm{~h}$ using ET-Kyoto solution (Otsuka Pharmaceutical Factory Inc, Tokushima, Japan) (30). The lungs in the HMP group were stored in an inflated state with oxygen fraction of 0.5 at $4{ }^{\circ} \mathrm{C}$ for $12 \mathrm{~h}$ using ET-Kyoto solution, and then reconditioned by $2 \mathrm{~h}$ of HMP. In both groups, the left lung was then transplanted to a recipient as previously described (29). The transplanted lung was 
1 reinflated and mechanically ventilated with $\mathrm{FiO}_{2}$ of 1.0 , and then reperfused for $4 \mathrm{~h}$

2 to evaluate the posttransplant lung functions. The right pulmonary artery was

3 occluded with a tourniquet $45 \mathrm{~min}$ after reperfusion to specifically evaluate the

4 functions of the transplanted lung. The pulmonary arterial pressure and peak

5 airway pressure (PawP) were continuously monitored throughout the experiments.

6 Dynamic pulmonary compliance was defined as tidal volume/(PawP - PEEP)

$7 \quad\left(\mathrm{ml} / \mathrm{cmH}_{2} \mathrm{O}\right)$. A blood gas analysis was performed using blood collected from the

8 femoral artery at selected time points. Lung tissue biopsy samples collected from

9 the left middle lobe $4 \mathrm{~h}$ after reperfusion were weighed to obtain the wet lung

10 weight, placed in an oven at $180^{\circ} \mathrm{C}$ for $24 \mathrm{~h}$, and then reweighed to obtain the dry

11 lung weight. The wet to dry lung weight ratio was calculated to evaluate the 12 presence of pulmonary edema.

14 Hypothermic machine perfusion (HMP)

15 The lungs were placed in an XVIVO chamber (Vitrolife, Denver, CO). The 16 pulmonary artery was cannulated directly and then connected to the perfusion 17 circuit. The left atrium was left open, so that the left atrial pressure was always 0 $18 \mathrm{mmHg}$. The trachea was intubated and connected to the ventilator. Mechanical 19 ventilation was started with $\mathrm{FiO}_{2}$ of 0.25 , tidal volume of $10 \mathrm{ml} / \mathrm{kg}$, frequency of 10 20 breaths/min and PEEP of $5 \mathrm{cmH}_{2} \mathrm{O}$. The perfusate, which contained STEEN 21 solution (1,500 ml) with methylprednisolone (500 mg) and heparin (10,000 IU), was 22 driven by a centrifugal pump at a constant flow rate of $10 \%$ of the estimated cardiac 23 output $(\mathrm{CO}=100 \mathrm{ml} / \mathrm{kg})$. Deoxygenation of the perfusate was started with a gas 24 mixture of nitrogen (86\%), carbon dioxide (8\%), and oxygen $(6 \%)$ to maintain the 
1 influent $\mathrm{PCO}_{2}$ of around $40 \mathrm{mmHg}$. The temperature of influent was continuously

2 monitored, and was maintained around $10{ }^{\circ} \mathrm{C} \quad(31)$. The influent solute

3 concentrations, $\mathrm{PO}_{2}$, and $\mathrm{PCO}_{2}$ levels were recorded every hour. The pulmonary

4 arterial pressure and peak airway pressure were continuously monitored, and the

5 physiological lung functions (dynamic pulmonary compliance and pulmonary

6 vascular resistance) during HMP were evaluated every 30 min. Recruitments were

7 performed to ensure a peak airway pressure of $25 \mathrm{cmH}_{2} \mathrm{O}$ every 30 min prior to each

8 evaluation. Dynamic pulmonary compliance was defined as described above.

9 Pulmonary vascular resistance was defined as (pulmonary arterial pressure - left

10 atrial pressure)/ pulmonary arterial flow $(\mathrm{mmHg} / \mathrm{L})$.

\section{Lung tissue ATP levels}

13 Lung tissue biopsy specimens were collected from the right lung before cardiac 14 arrest and after warm ischemia, and then were collected from the left upper lobe $4 \mathrm{~h}$ 15 after reperfusion. ATP levels were measured by high-performance liquid 16 chromatography using a Shim-pack CLC-ODS column $(15 \mathrm{~cm} \times 6.0 \mathrm{~mm}$; Shimadzu, 17 Japan) and $100 \mathrm{mM}$ sodium phosphate buffer (PH 6.0) at a wavelength of $260 \mathrm{~nm}$, 18 as described previously (32).

\section{Malondialdehyde levels}

21 Malondialdehyde levels were measured with the NWLSS Malondialdehyde Assay

22 kit from Northwest (Northwest Life Sciences Specialties, Vancouver, Canada)

23 following the manufacture's protocol. Malondialdehyde (MDA) reacted with

24 thiobarbituric acid (TBA), forming an $\mathrm{MDA}^{-\mathrm{TBA}_{2}}$ adduct that was measured at a 
$1 \quad$ wavelength of $532 \mathrm{~nm}$.

2

3 Cytokine levels in BAL fluid

4 BAL was performed with $20 \mathrm{ml}$ of saline using a flexible bronchoscope wedged into

5 the left lower bronchus. Collected samples were centrifuged at 1,500g for $10 \mathrm{~min}$ at

$644^{\circ} \mathrm{C}$, and then the supernatant was stored at $-80^{\circ} \mathrm{C}$ to evaluate the cytokine levels.

7 TNF- $\alpha$ and IL-6 levels were measured with a Quantikine ELISA kit (R\&D

8 Systems Inc., Minneapolis, MN, USA) following the protocol developed by the 9 manufacture.

\section{Histological evaluation of microthrombi and ischemia-reperfusion injury}

12 Lung tissue biopsies were collected from the right lower lobe just before 13 transplantation and the left lower lobe $4 \mathrm{~h}$ after reperfusion. They were fixed in $10 \%$

14 buffered formalin, embedded in paraffin, and stained with hematoxylin and eosin.

15 Five sections including capillaries were examined by blinded investigators (A.O. and J.S.) to evaluate the residual microthrombi in the donor lungs. The extent of

17 ischemia-reperfusion injury was scored blindly by two investigators (A.O. and J.S.) using a four-point scale according to the combined assessment of edema (interstitial

\section{Statistical analysis}

24 All data are presented as means \pm standard deviation. The statistical analysis 
1

2

3

4

5

6

7

8

9

10

11

12

13

14

15

16

17

18

19

20

21

22

23

24

25

26

27

28

29

30

31

32

33

34

35

36

37

38

39

40

41

42

43

44

45

46

47

48

49

50

51

52

53

54

55

56

57

58

59

60
1 was performed using Student's $t$-test and a repeated-measures analysis of variance

2 (ANOVA). A p value $<0.05$ was considered to be statistically significant.

4 


\section{References}

2 1. Steen S, Sjoberg T, Pierre L, Liao Q, Eriksson L, Algotsson L. Transplantation of

3 lungs from a non-heart-beating donor. Lancet 2001;357(9259):825.

4 2. Gomez-de-Antonio D, Campo-Canaveral JL, Crowley S, et al. Clinical lung

5 transplantation from uncontrolled non-heart-beating donors revisited. J.Heart

$6 \quad$ Lung Transplant. 2012;31(4):349.

7 3. Gamez P, Cordoba M, Ussetti P, et al. Lung transplantation from out-of-hospital

8 non-heart-beating lung donors. one-year experience and results. J.Heart Lung

$9 \quad$ Transplant. 2005;24(8):1098.

10 4. de Perrot M, Liu M, Waddell TK, Keshavjee S. Ischemia-reperfusion-induced

11 lung injury. Am.J.Respir.Crit.Care Med. 2003;167(4):490.

12 5. Fujinaga T, Nakamura T, Fukuse T, et al. Isoflurane inhalation after circulatory

13 arrest protects against warm ischemia reperfusion injury of the lungs.

$14 \quad$ Transplantation 2006;82(9):1168.

15 6. Jassem W, Heaton ND. The role of mitochondria in ischemia/reperfusion injury in 16 organ transplantation. Kidney Int. 2004;66(2):514. 
1 7. Boros P, Bromberg JS. New cellular and molecular immune pathways in

2 ischemia/reperfusion injury. Am.J.Transplant. 2006;6(4):652.

3 8. Moers C, Smits JM, Maathuis MH, et al. Machine perfusion or cold storage in

4 deceased-donor kidney transplantation. N.Engl.J.Med. 2009;360(1):7.

5 9. Guarrera JV, Henry SD, Samstein B, et al. Hypothermic machine preservation in

6 human liver transplantation: the first clinical series. Am.J.Transplant.

$7 \quad 2010 ; 10(2): 372$.

8 10. Dutkowski P, de Rougemont O, Clavien PA. Machine perfusion for 'marginal'

9 liver grafts. Am.J.Transplant. 2008;8(5):917.

10 11. Nakajima D, Chen F, Yamada T, et al. Hypothermic machine perfusion

11 ameliorates ischemia-reperfusion injury in rat lungs from non-heart-beating donors.

12 Transplantation 2011;92(8):858.

13 12. de Zwart LL, Meerman JH, Commandeur JN, Vermeulen NP. Biomarkers of

14 free radical damage applications in experimental animals and in humans. Free

$15 \quad$ Radic.Biol.Med. 1999;26(1-2):202. 
1 13. de Antonio DG, Marcos R, Laporta R, et al. Results of clinical lung transplant

2 from uncontrolled non-heart-beating donors. J.Heart Lung Transplant.

$3 \quad 2007 ; 26(5): 529$.

4 14. Rauen U, Petrat F, Li T, De Groot H. Hypothermia injury/cold-induced

5 apoptosis--evidence of an increase in chelatable iron causing oxidative injury in

6 spite of low O2-/H2O2 formation. FASEB J. 2000;14(13):1953.

7 15. Dutkowski P, Furrer K, Tian Y, Graf R, Clavien PA. Novel short-term

8 hypothermic oxygenated perfusion (HOPE) system prevents injury in rat liver graft

9 from non-heart beating donor. Ann.Surg. 2006;244(6):968.

10 16. Dutkowski P, Graf R, Clavien PA. Rescue of the cold preserved rat liver by

11 hypothermic oxygenated machine perfusion. Am.J.Transplant. 2006;6(5 Pt 1):903.

12 17. Van De Wauwer C, Neyrinck AP, Geudens N, et al. Retrograde flush following

13 warm ischemia in the non-heart-beating donor results in superior graft

14 performance at reperfusion. J.Surg.Res. 2009;154(1):118. 
1 18. Wittwer T, Franke UF, Fehrenbach A, et al. Experimental lung transplantation:

2 impact of preservation solution and route of delivery. J.Heart Lung Transplant.

$3 \quad 2005 ; 24(8): 1081$.

4 19. Hayama M, Date H, Oto T, Aoe M, Andou A, Shimizu N. Improved lung function

5 by means of retrograde flush in canine lung transplantation with non-heart-beating

6 donors. J.Thorac.Cardiovasc.Surg. 2003;125(4):901.

7 20. Taylor MJ, Baicu SC. Current state of hypothermic machine perfusion

8 preservation of organs: The clinical perspective. Cryobiology 2010;60(3 Suppl):S20.

9 21. Hong SB, Koh Y, Lee IC, et al. Induced hypothermia as a new approach to lung

10 rest for the acutely injured lung. Crit.Care Med. 2005;33(9):2049.

11 22. Date H, Matsumura A, Manchester JK, Cooper JM, Lowry OH, Cooper JD.

12 Changes in alveolar oxygen and carbon dioxide concentration and oxygen

13 consumption during lung preservation. The maintenance of aerobic metabolism

14 during lung preservation. J.Thorac.Cardiovasc.Surg. 1993;105(3):492. 
1 23. Cypel M, Rubacha M, Yeung J, et al. Normothermic ex vivo perfusion prevents

2 lung injury compared to extended cold preservation for transplantation.

3 Am.J.Transplant. 2009;9(10):2262.

4 24. Cypel M, Yeung JC, Liu M, et al. Normothermic ex vivo lung perfusion in

$5 \quad$ clinical lung transplantation. N.Engl.J.Med. 2011;364(15):1431.

6 25. Ingemansson R, Eyjolfsson A, Mared L, et al. Clinical transplantation of initially

7 rejected donor lungs after reconditioning ex vivo. Ann.Thorac.Surg. 2009;87(1):255.

8 26. Inci I, Ampollini L, Arni S, et al. Ex vivo reconditioning of marginal donor lungs

9 injured by acid aspiration. J.Heart Lung Transplant. 2008;27(11):1229.

10 27. Hosgood SA, Nicholson ML. First in man renal transplantation after ex vivo

11 normothermic perfusion. Transplantation 2011;92(7):735.

12 28. Van de Wauwer C, Neyrinck AP, Geudens N, et al. The mode of death in the

13 non-heart-beating donor has an impact on lung graft quality.

14 Eur.J.Cardiothorac.Surg. 2009;36(5):919. 
1 29. Nakajima D, Chen F, Yamada T, et al. Reconditioning of lungs donated after

$3 \quad$ Transplant. 2012;31(2):187.

4 30. Chen F, Nakamura T, Wada H. Development of new organ preservation

5 solutions in Kyoto University. Yonsei Med.J. 2004;45(6):1107.

6 31. Date H, Lima O, Matsumura A, Tsuji H, d'Avignon DA, Cooper JD. In a canine

7 model, lung preservation at 10 degrees $\mathrm{C}$ is superior to that at 4 degrees $\mathrm{C}$. A

8 comparison of two preservation temperatures on lung function and on adenosine

9 triphosphate level measured by phosphorus 31-nuclear magnetic resonance.

10 J.Thorac.Cardiovasc.Surg. 1992;103(4):773.

11 32. Chen F, Nakamura T, Fujinaga T, et al. Protective effect of a nebulized

12 beta2-adrenoreceptor agonist in warm ischemic-reperfused rat lungs.

13 Ann.Thorac.Surg. 2006;82(2):465.

14 33. Bregeon F, Papazian L, Delpierre S, et al. Role of proinflammatory activity

15 contained in gastric juice from intensive care unit patients to induce lung injury in a

16 rabbit aspiration model. Crit.Care Med. 2008;36(12):3205. 
1

2

3

4

5

6

7

8

9

10

11

12

13

14

15

16

17

18

19

20

21

22

23

24

25

26

27

28

29

30

31

32

33

34

35

36

37

38

39

40

41

42

43

44

45

46

47

48

49

50

51

52

53

54

55

56

57

58

59

60
1 34. Frank JA, Pittet JF, Wray C, Matthay MA. Protection from experimental

2 ventilator-induced acute lung injury by IL-1 receptor blockade. Thorax

$3 \quad 2008 ; 63(2): 147$.

5 
$1 \quad$ Figure legends

2 FIGURE 1. Physiological lung functions during HMP: Dynamic pulmonary

3 compliance (A). Pulmonary vascular resistance (B). ${ }^{*} \mathrm{P}<0.05$ versus the baseline

4 data. Residual microthrombi in the donor lungs just before transplantation in the

$5 \quad$ SCS group (C) and in the HMP group (D). Arrows indicate residual microthrombi in

6 the capillaries. HMP: hypothermic machine perfusion, SCS: static cold storage.

8 FIGURE 2. Lung tissue ATP levels before cardiac arrest, after warm ischemia, and

$94 \mathrm{~h}$ after reperfusion. ${ }^{*} \mathrm{P}<0.05$. ATP: adenosine triphosphate, HMP: hypothermic

10 machine perfusion, SCS: static cold storage.

12 FIGURE 3. Malondialdehyde (MDA) levels in the perfusate during $\operatorname{HMP}(\mathrm{A})$ and in

13 the serum $4 \mathrm{~h}$ after reperfusion (B). ${ }^{*} \mathrm{P}<0.05$. TNF- $\alpha$ levels $(\mathrm{C})$ and IL-6 levels (D)

14 in the BAL fluid $4 \mathrm{~h}$ after reperfusion. $\dagger \mathrm{P}<0.01, * \mathrm{P}<0.05$. BAL: bronchoalveolar

15 lavage, HMP: hypothermic machine perfusion, SCS: static cold storage.

16

17 FIGURE 4. Physiological lung functions during reperfusion. The right pulmonary

18 artery was occluded $45 \mathrm{~min}$ after reperfusion to evaluate the functions of the 
1 transplanted lung only. $\uparrow$ These data show the physiological lung functions of the

2 bilateral lungs (native lung and transplanted lung) before the clamp of the right

3 pulmonary artery. $\mathrm{PaO}_{2}$ (A) and dynamic pulmonary compliance (B) were

4 significantly better in the HMP group (solid circles) than in the SCS group (open

5 boxes); $\mathrm{P}<0.01$. Wet to dry lung weight ratio $4 \mathrm{~h}$ after reperfusion $(\mathrm{C}) .{ }^{*} \mathrm{P}<0.05$.

6 HMP: hypothermic machine perfusion, SCS: static cold storage.

7

8 FIGURE 5. Acute lung injury score: Ischemia-reperfusion injury was scored using a

9 four-point scale according to the combined assessment of edema, hemorrhage, cell

10 infiltration, and hyaline membrane formation. $\dagger \mathrm{P}<0.01$. HMP: hypothermic

11 machine perfusion, SCS: static cold storage. 


\section{FIGURE 1.}

A

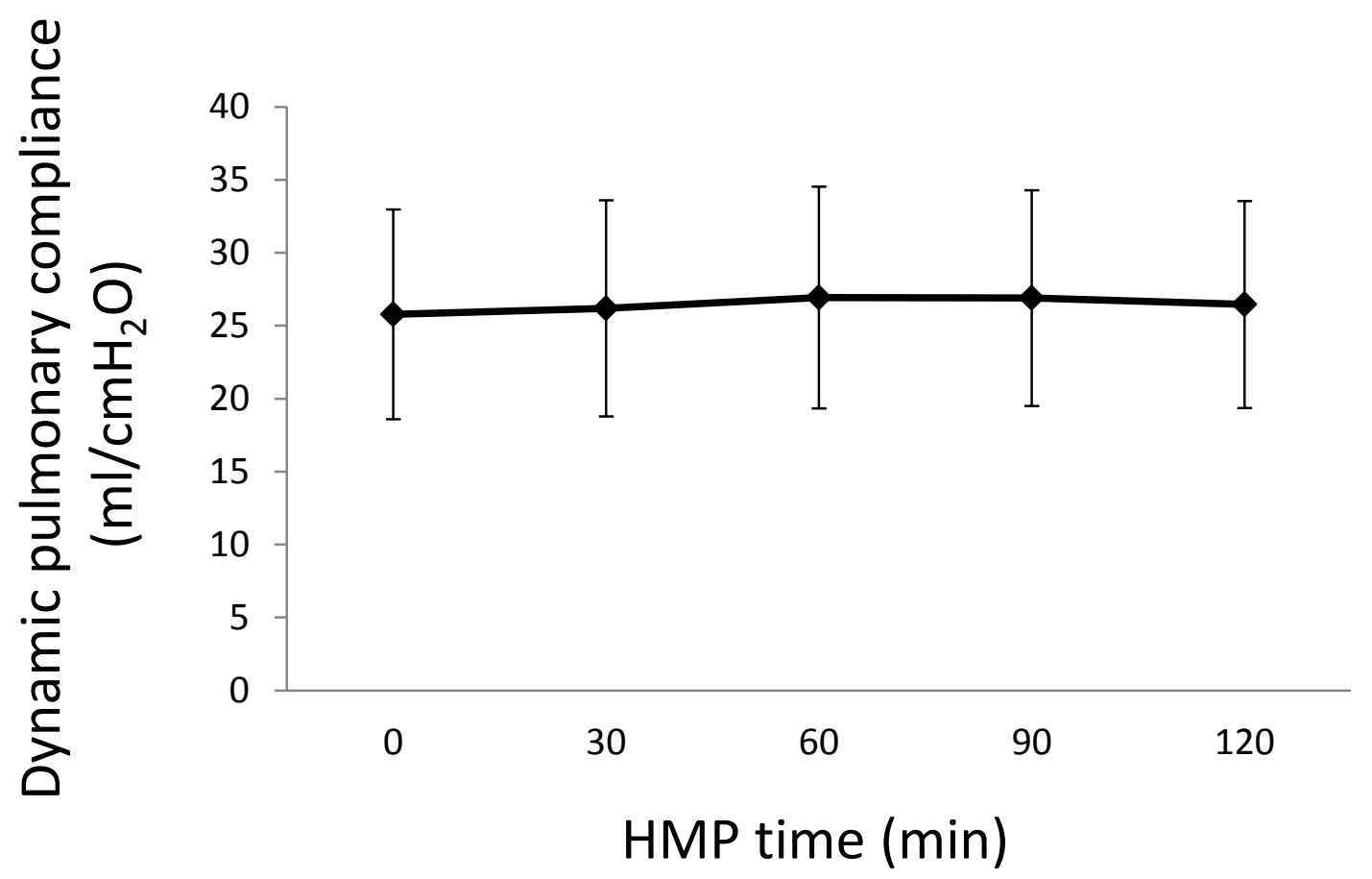

ScholarOne support: (434) 9644100 


\section{FIGURE 1.}

\section{B}

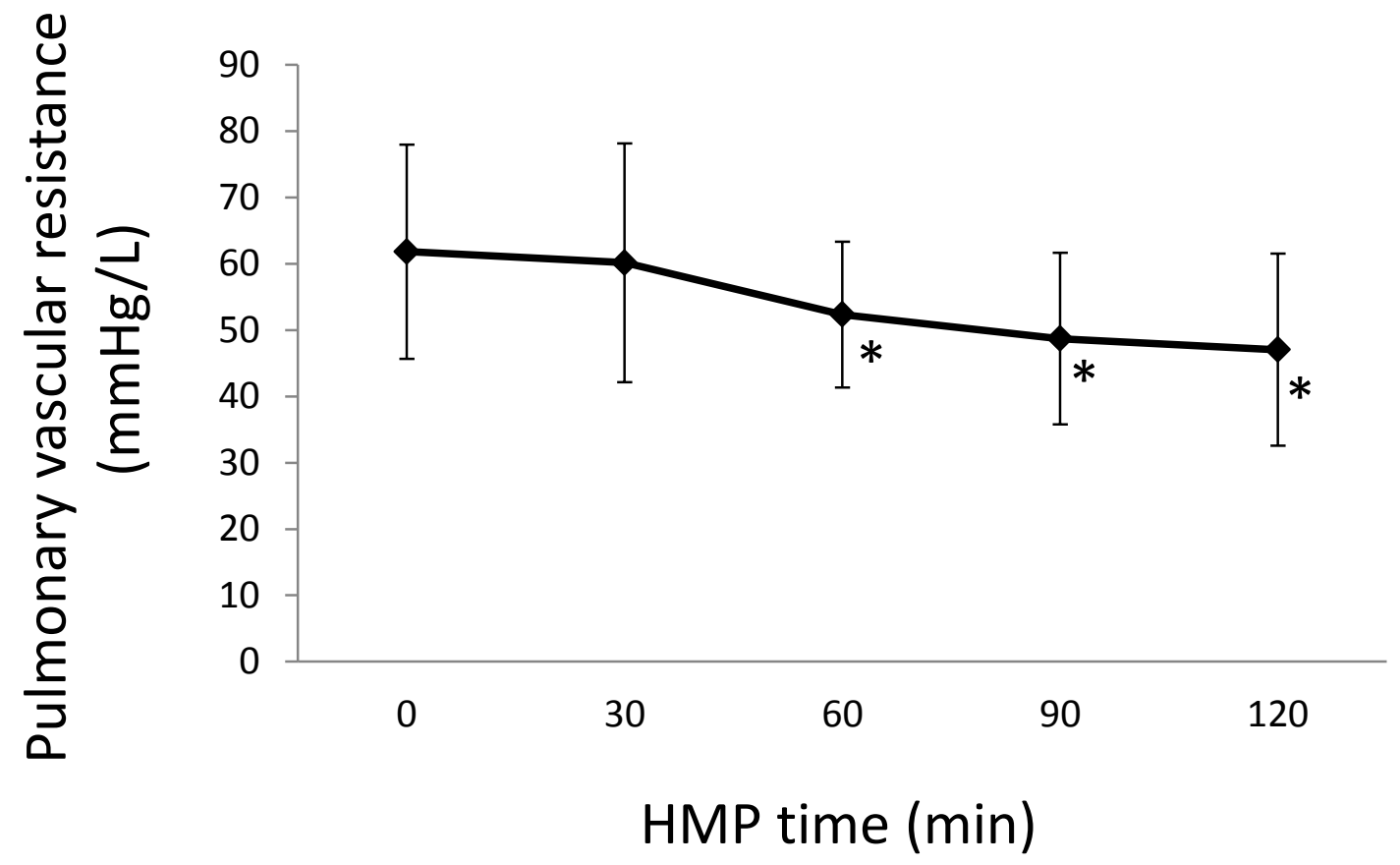




\section{FIGURE 1.}

C

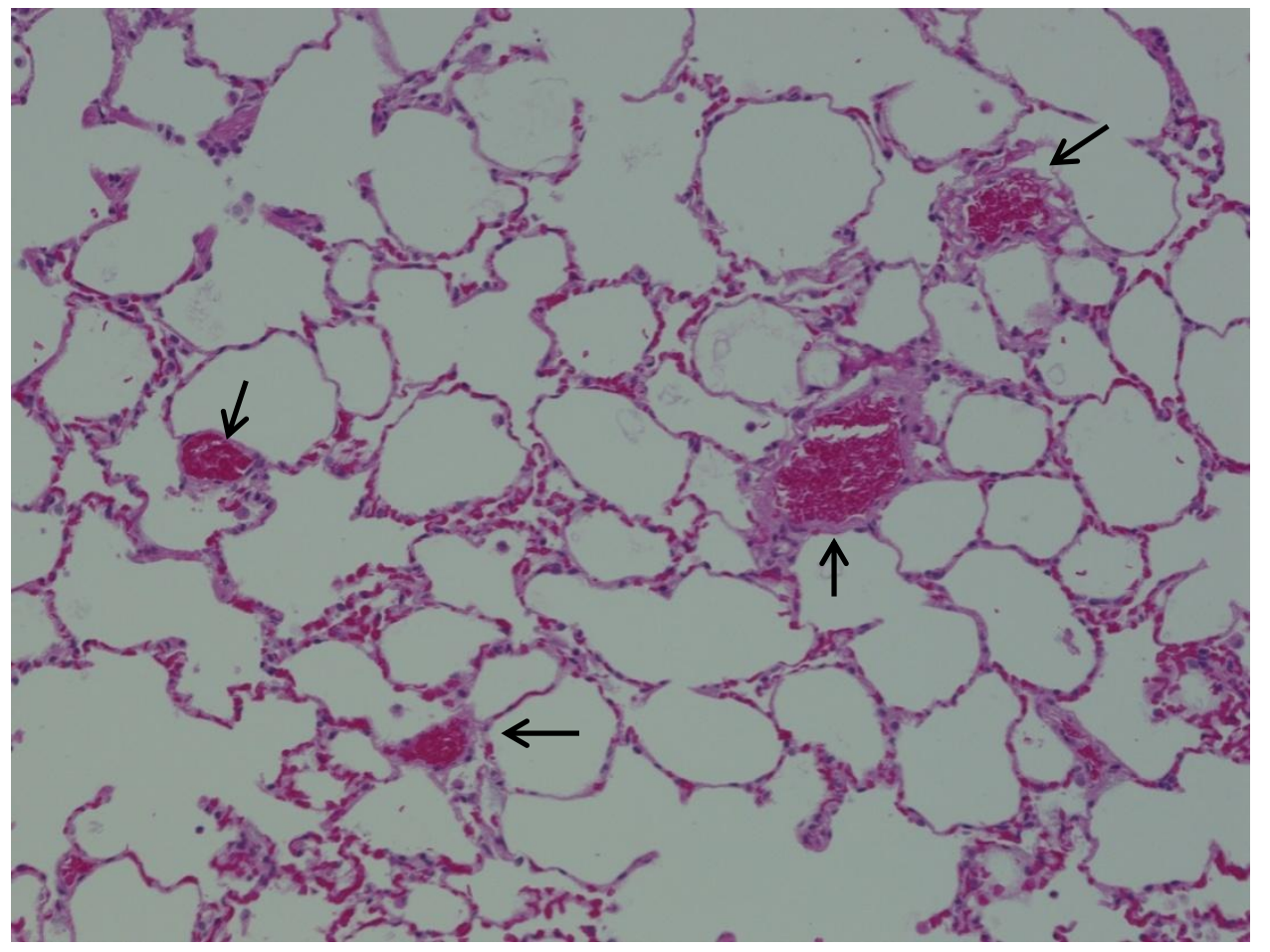

ScholarOne support: (434) 9644100 


\section{FIGURE 1.}

D

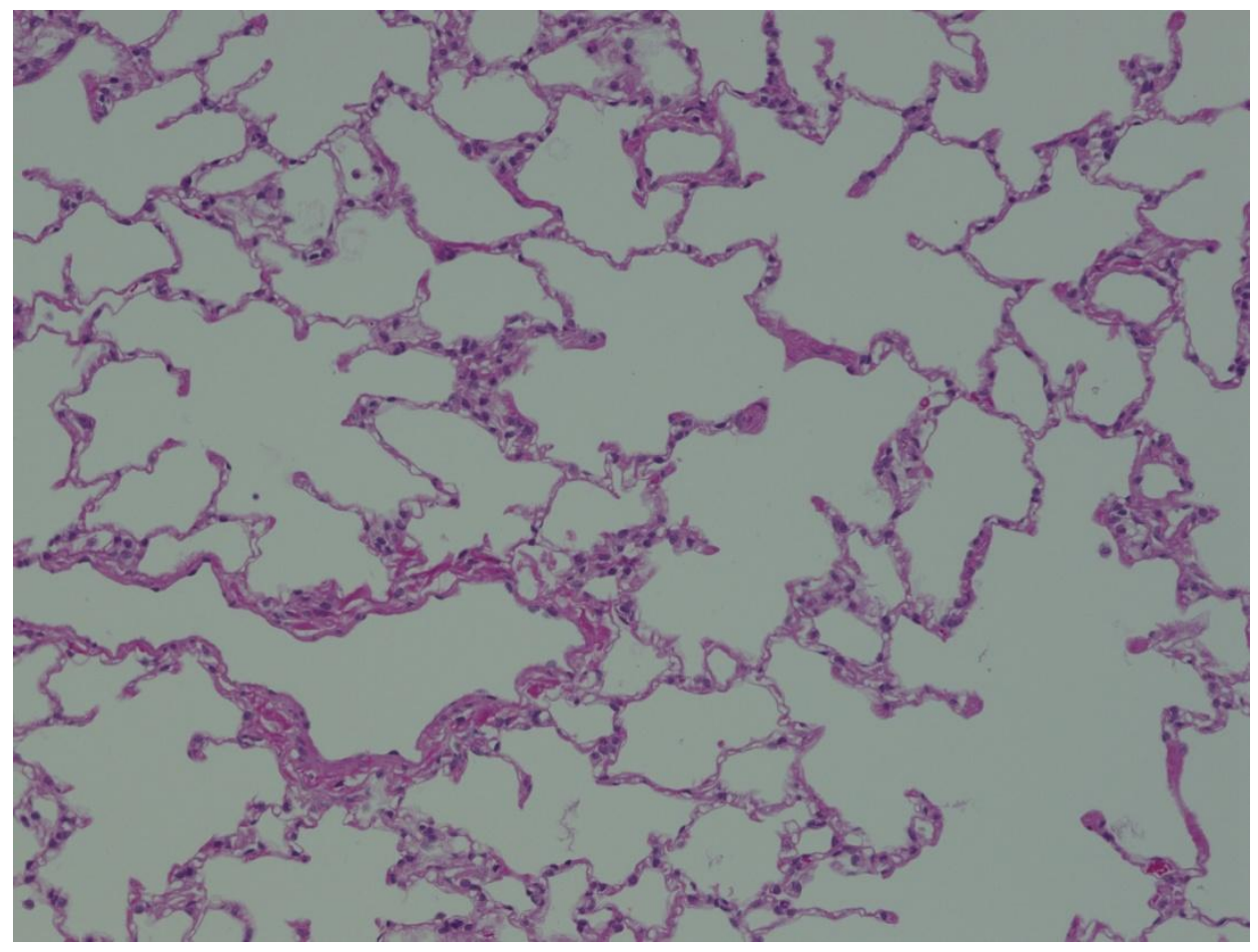

ScholarOne support: (434) 9644100 


\section{FIGURE 2.}

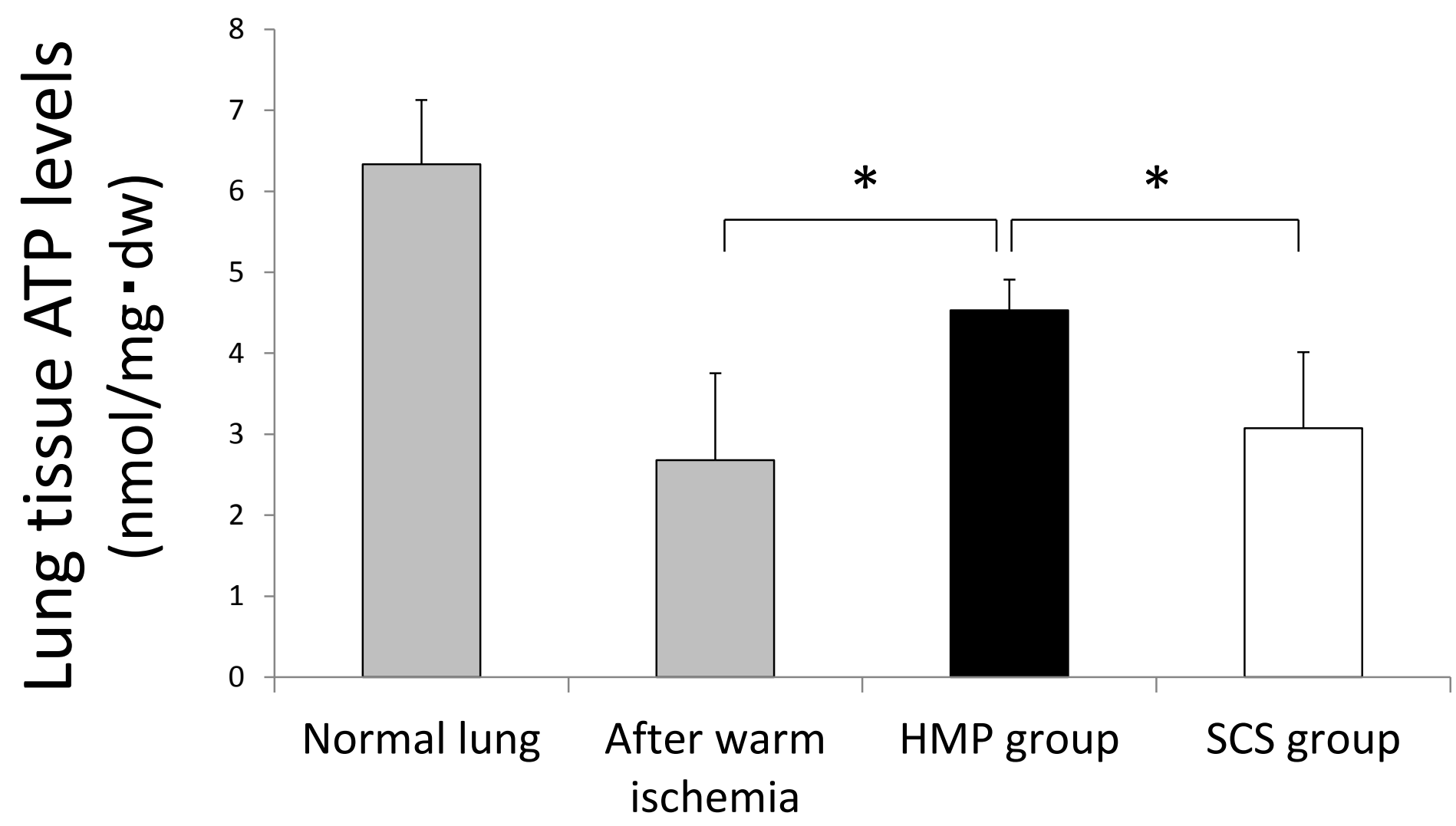

ScholarOne support: (434) 9644100 


\section{FIGURE 3.}

A

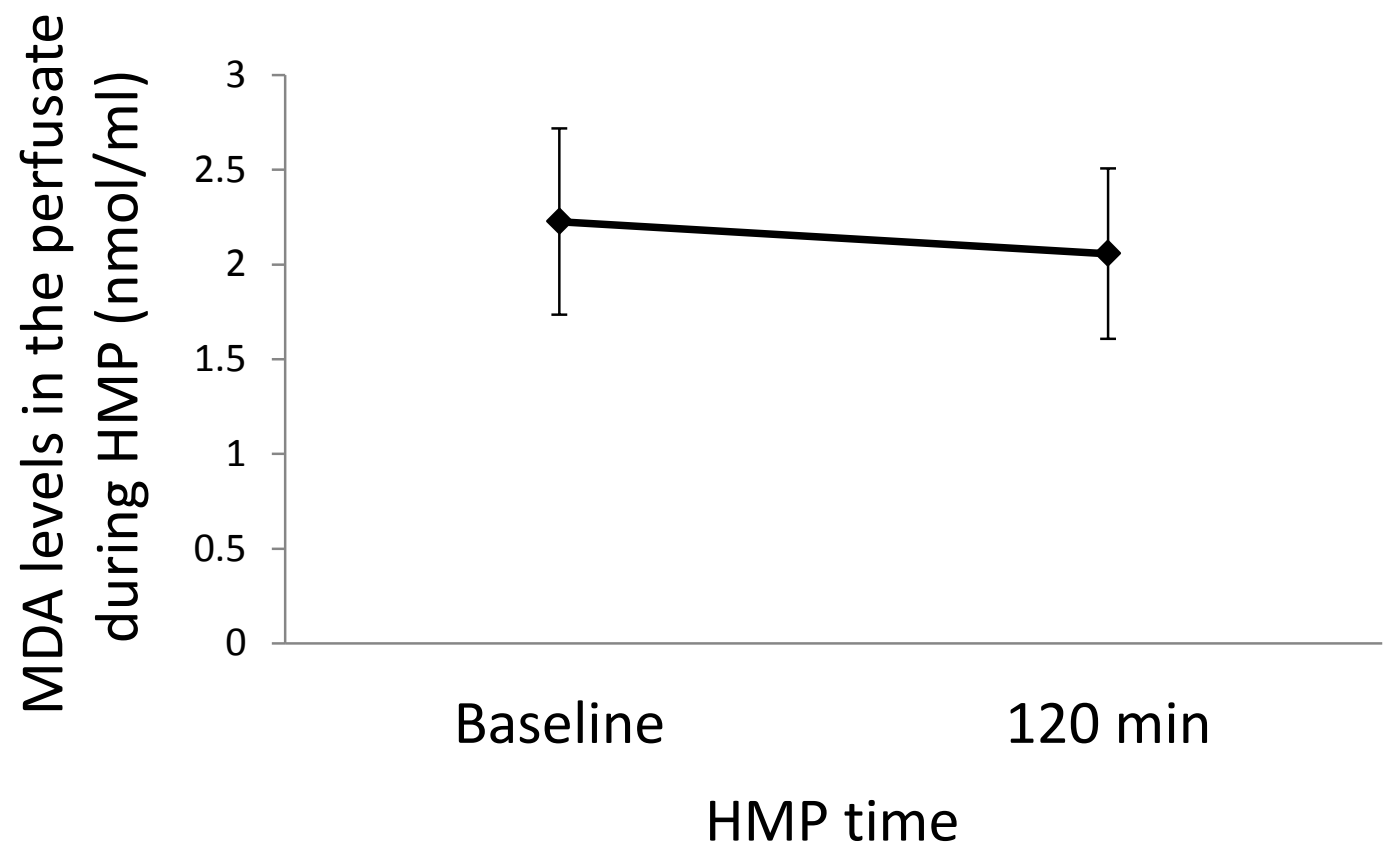

ScholarOne support: (434) 9644100 


\section{FIGURE 3.}

B

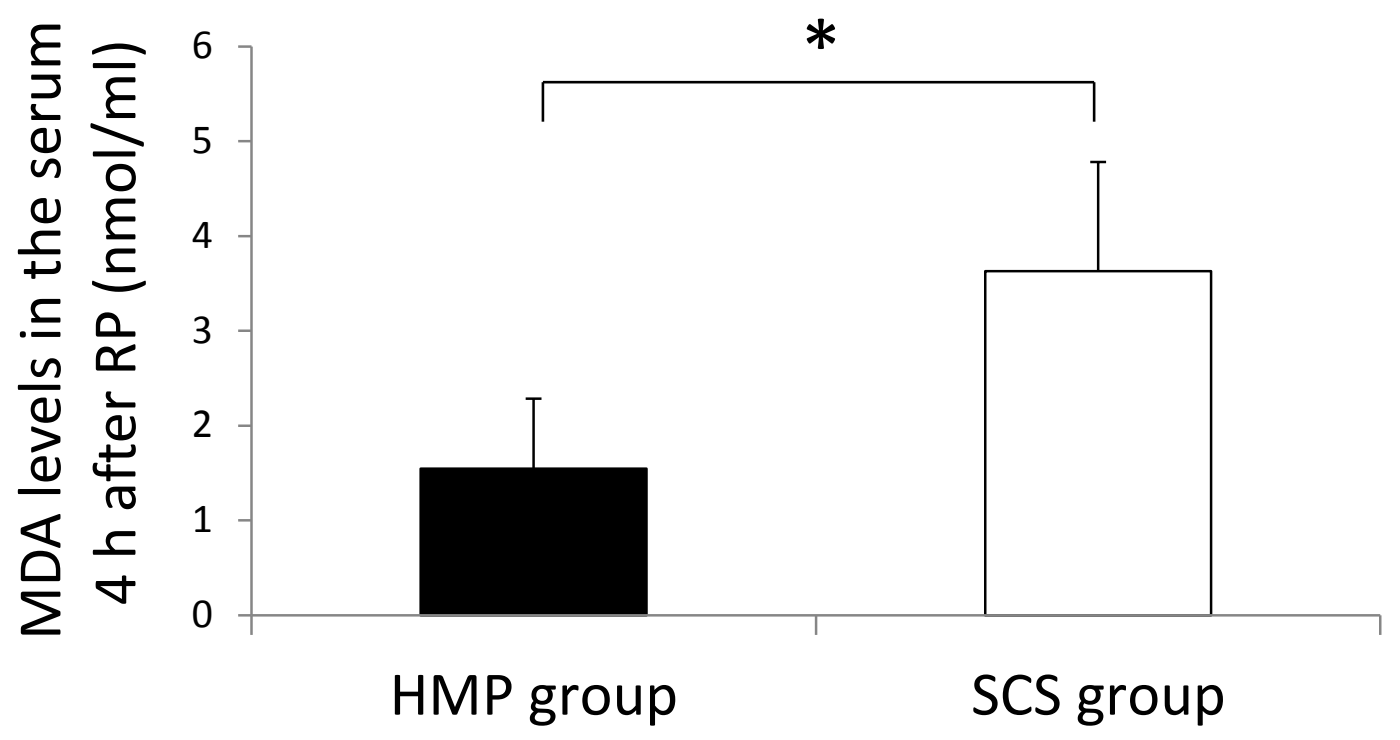




\section{FIGURE 3.}

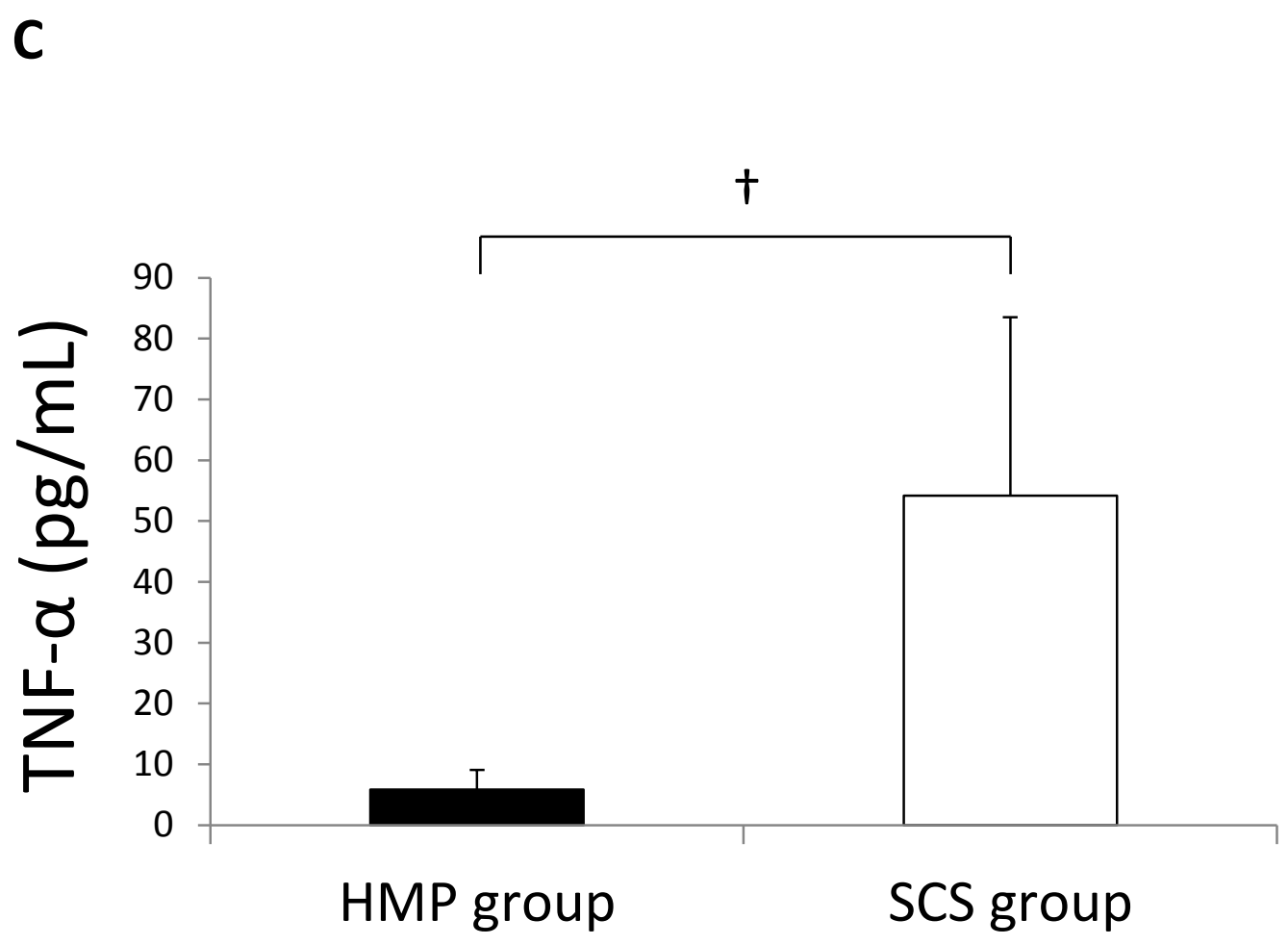




\section{FIGURE 3.}

D

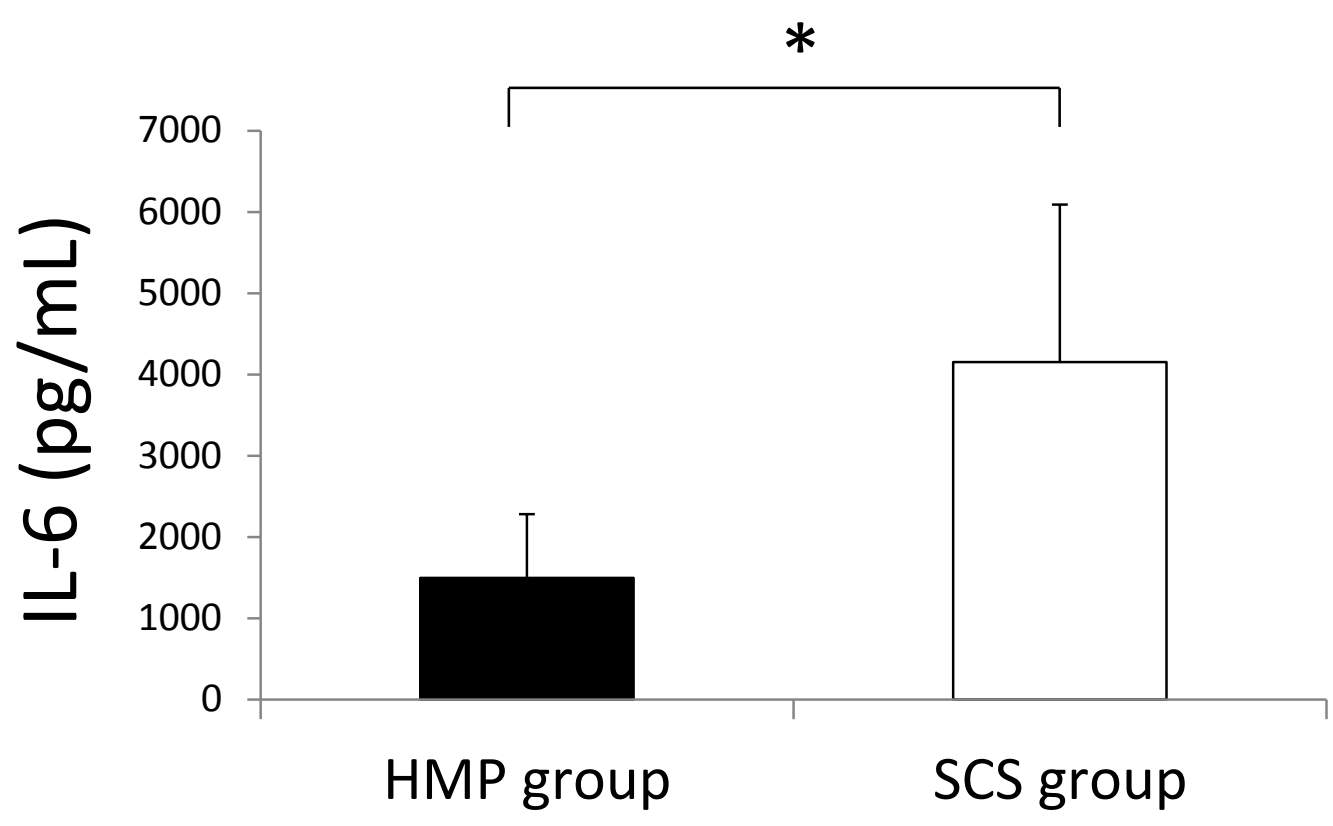

ScholarOne support: (434) 9644100 


\section{FIGURE 4.}

A

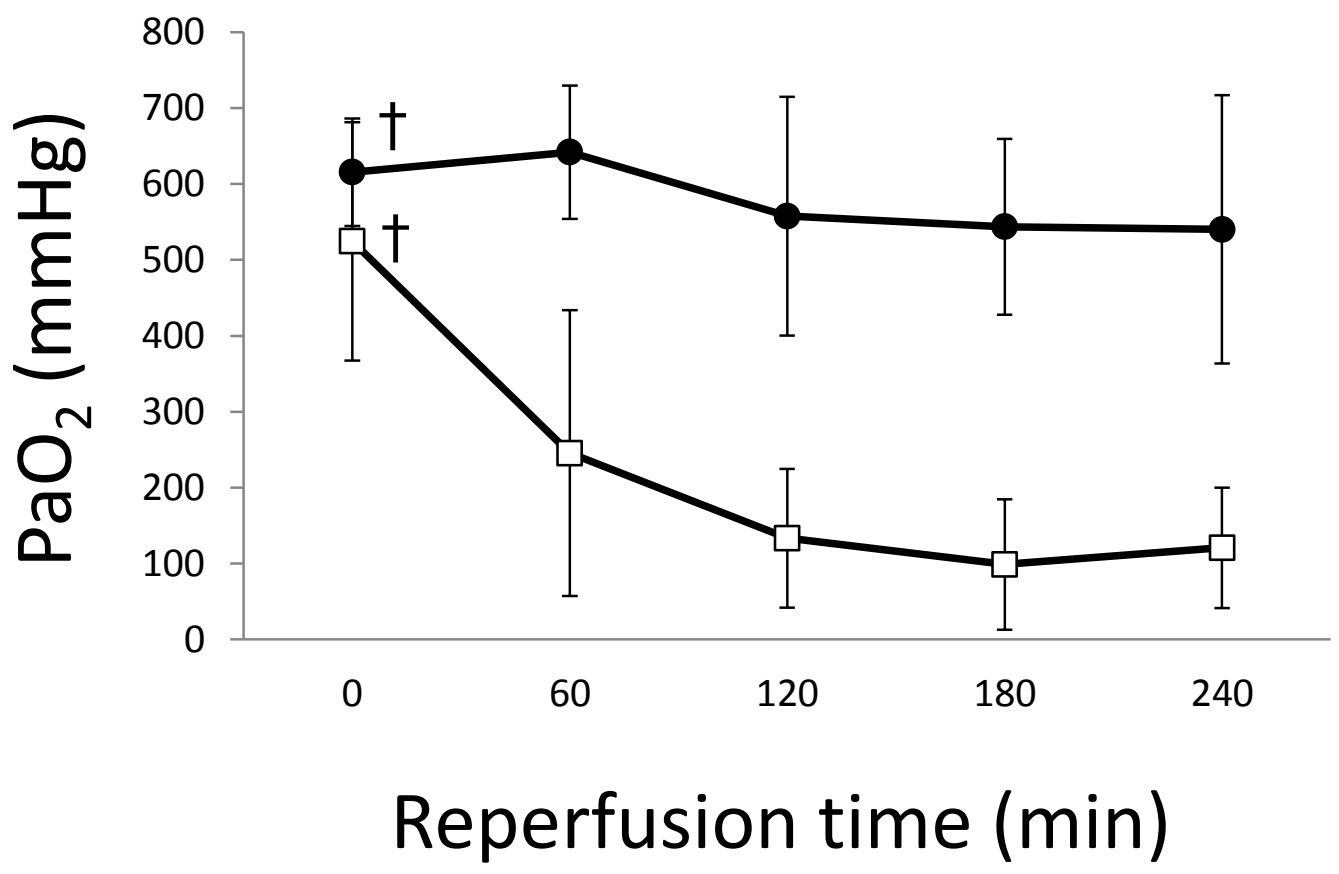

ScholarOne support: (434) 9644100 


\section{FIGURE 4.}

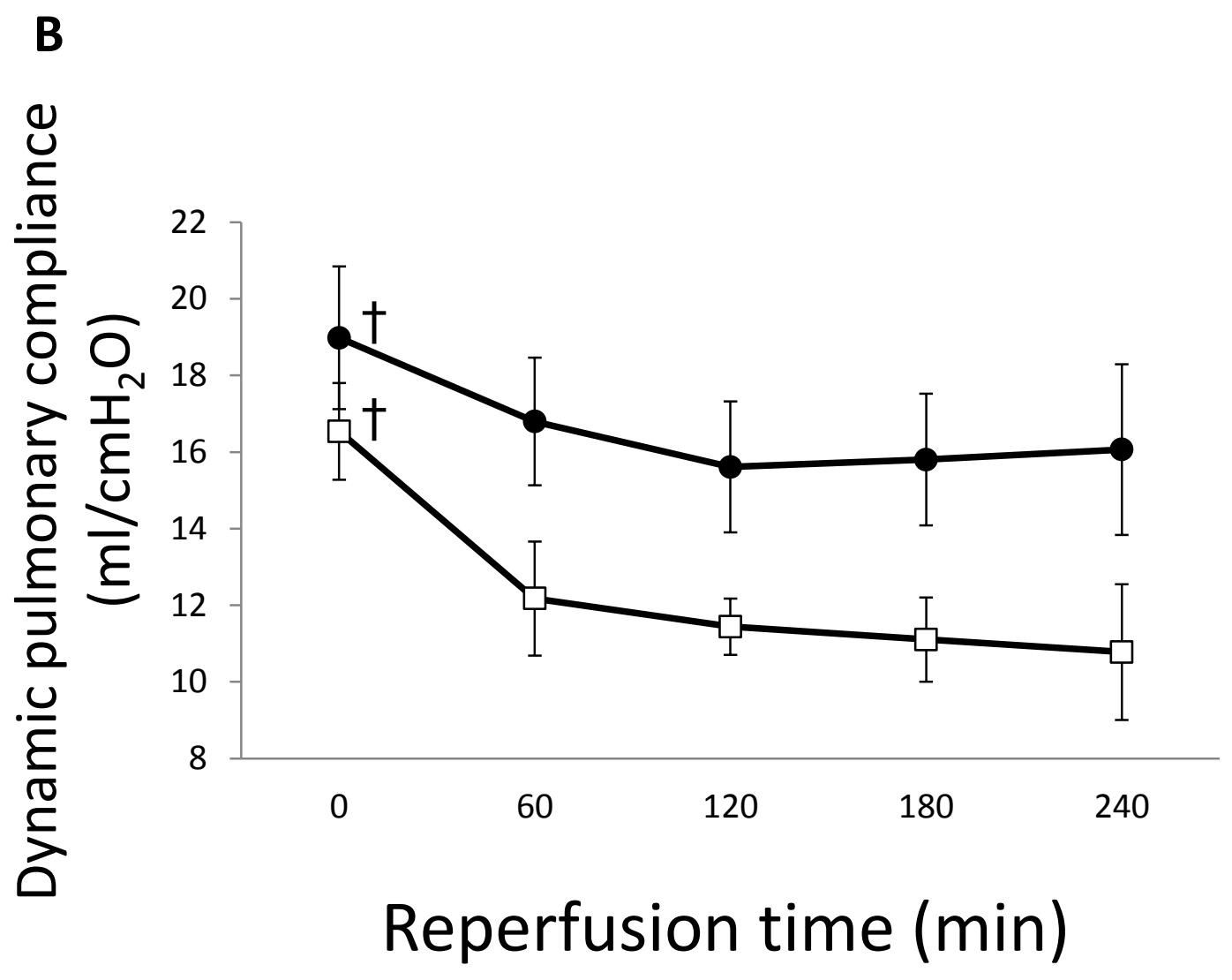

ScholarOne support: (434) 9644100 


\section{FIGURE 4.}

C

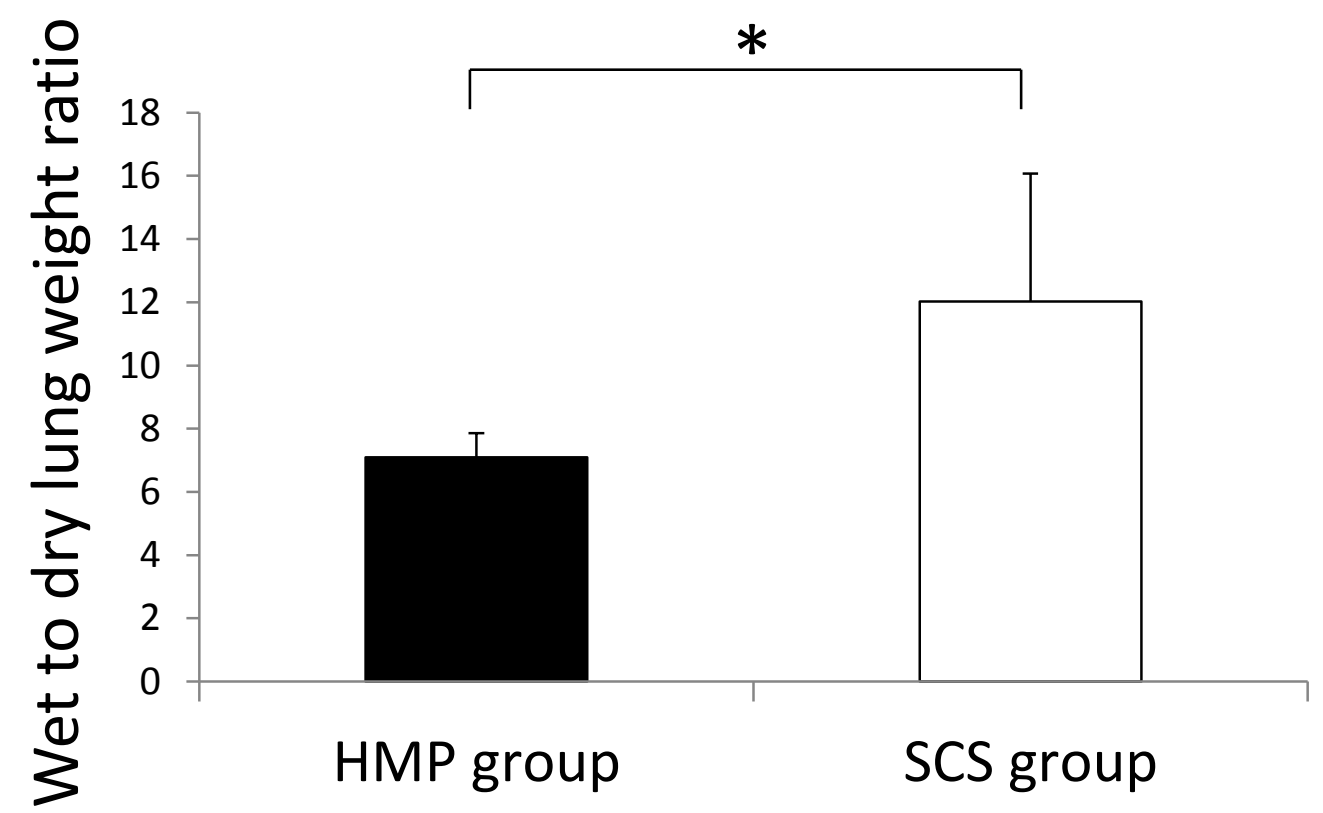




\section{FIGURE 5.}

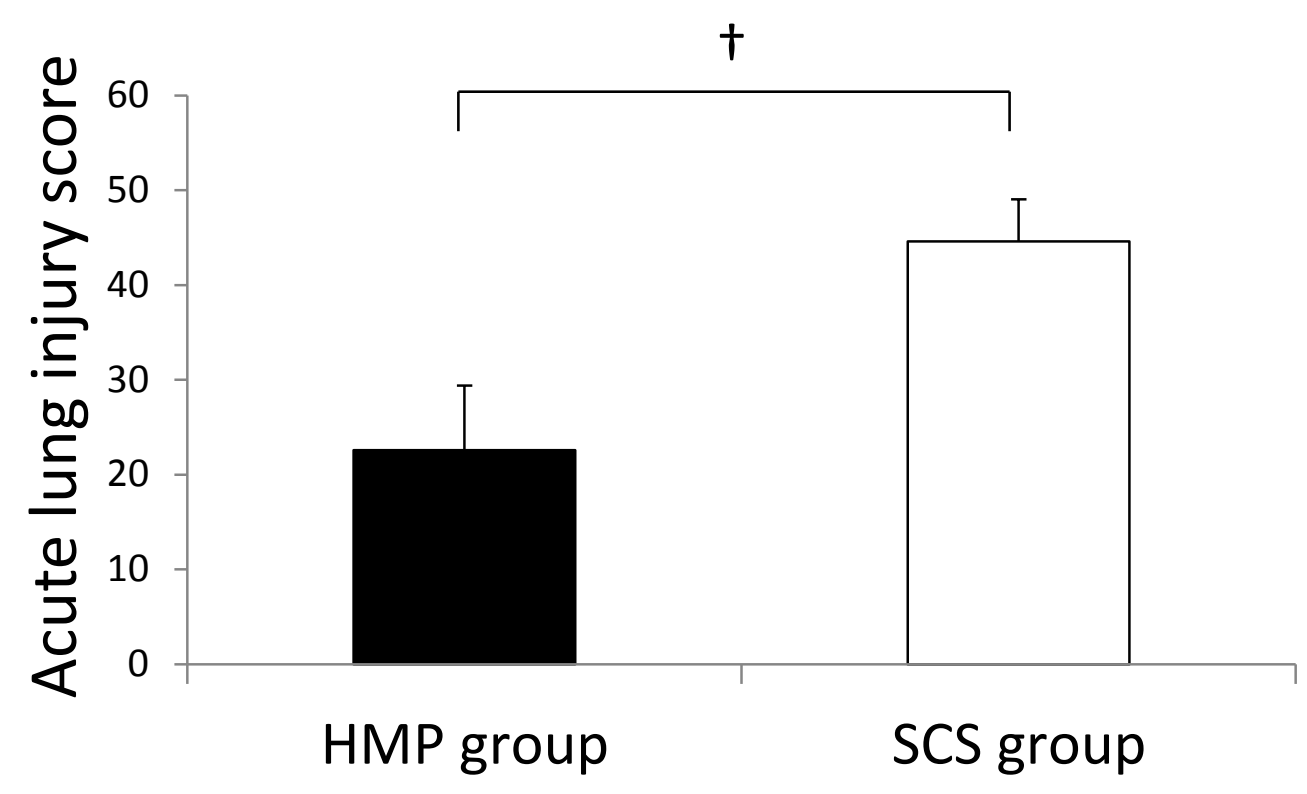

